\title{
Fracture mechanics and fatigue life assessment of box-shaped welded structures: FEM analysis and parametric design
}

\author{
E. Delkhosh ${ }^{1} \cdot$ M. Khurshid ${ }^{1,2}$ (D) I. Barsoum $^{3} \cdot$ Z. Barsoum $^{1}$
}

Received: 2 September 2019 / Accepted: 15 June 2020 / Published online: 25 June 2020

(C) The Author(s) 2020

\begin{abstract}
In this study, Linear Elastic Fracture Mechanics (LEFM) approach is used to evaluate the fatigue strength of a box-shaped welded structure. A parametric study is also undertaken to study the effect of various weld parameters on the fatigue strength, such as lack of weld metal penetration, load position, and plate thicknesses. FRANC3D software was adopted to obtain the stress intensity factor values for two types of full-length and intermediate crack sizes, located at the critical region of the weld of the box-shaped structure. It was concluded that the LEFM approach could capture the crack propagation from the weld root reasonably well under the given conditions and estimate residual fatigue life of the welded structures conservatively. Compared to fatigue life estimations by nominal stress method (1,714,564 cycles) or effective notch stress method (63,385 cycles), the LEFM approach can estimate the residual life more accurately. Especially for intermediate $(4 \mathrm{~mm})$ lack of penetration (LOP) of weld metal case ( 589,198 cycles) in comparison to the experiments $(1,216,595$ cycles). The parametric study showed that the fatigue life increases with increase in the thickness of flanges, lesser LOP in the weld root, and when load is applied more toward the center of the plate.
\end{abstract}

Keywords Fatigue crack growth · Welded structures · Linear Elastic Fracture Mechanic · Stress intensity factor · Finite element method

\section{Introduction}

There are many methods for evaluating the fatigue life of welded structures [1]. In addition to direct experimental methods, procedures based on S-N curves and fatigue crack propagation (FCP) considerations are frequently used. Due to the inherent disadvantage of the S-N curve approach, which cannot describe crack propagation [2], an alternative approach based on Fracture Mechanics (FM) concepts has been developed. Linear Elastic Fracture Mechanics (LEFM) as the basic

Recommended for publication by Commission XIII - Fatigue of Welded Components and Structures

M. Khurshid

mansoor.khurshid@bromma.com

1 Department of Engineering Mechanics, Royal Institute of Technology, KTH, Teknikringen 08, 10044 Stockholm, Sweden

2 Cargotec Sweden AB Bromma Conquip, Kronborgsgränd 23, 16446 Kista, Sweden

3 Department of Mechanical Engineering, Khalifa University, P.O. Box 2533, Abu Dhabi, United Arab Emirates theory of fracture mechanics, is a state-of-art and effective approach to evaluate the fatigue strength, although it is conservative and its applicability is limited to small-scale yielding. This concept was first introduced by Paris et al. [3] and connects crack propagation rate with elastic stress intensity factor (SIF) to evaluate the fatigue life. In FM, SIF plays an inevitable role for fatigue life calculation of welded joints and its determination is necessary for the Paris' law. SIF describes the stress state at a crack tip caused by a remote load or residual stresses. The numerical techniques based on the finite element method (FEM) and boundary element method (BEM) are frequently used to calculate the stress intensity factors and crack increments including their direction. This approach is also implemented in many $2 \mathrm{D}$ and $3 \mathrm{D}$, commercial, and non-commercial software tools, such as FRANC2D and FRANC3D [4].

In welded joints, fatigue cracks can initiate either at the weld toe or the weld root. The latter may be affected by small irregularities or even by non-fused root faces forming a narrow opening which can be considered as an initial crack $[1,5,6]$. The fatigue strength of joints that fail from the root depends on many variables such as weld throat size, plate thickness, and depth of weld penetration. The last two parameters are defining the size of the pre- 
existing defect at the root. Frank and Fisher [7] found an expression using FEM to calculate the SIF at the tip of the weld root and indicated that main factors affecting the fatigue strength were plate thickness, weld size, and weld penetration depth. Guha [8] estimated fatigue life of cruciform joint failing from root due to lack of weld metal penetration (LOP) and compared the results with the experimental data. Petinov et al. [9] employed 3D FEM in order to simulate the fatigue behavior of boxing fillet-welded joints in both full and partial penetration conditions. Barsoum et al. [10] developed a 2D subroutine for LEFM analysis in order to study the interaction between residual stresses and external fatigue loading. Compressive residual stresses were found at the weld root, which enhanced the fatigue life. Mori [11] performed parametric FCP analysis and fatigue tests on two types of specimens with different weld penetrations and size to indicate the significant influence of bi-axial loading on the fatigue strength. Aygül et al. [12] studied the behavior of distortion induced fatigue cracks in welded details by performing crack propagation analysis based on LEFM. Triamlumlerda and Lenwari [13] simulated the FCP in steel I-beams numerically. They reported the effects of initial crack size, fillet weld size, stiffener dimension, and web-gap length on the FCP. All these efforts show the applicability of using LEFM in fatigue life estimation of welded structures specially when there is a LOP in the weld root.

A Round Robin study was conducted on box-welded structures with the purpose of studying the scatter between different fatigue strength assessment methodologies [14]. It was concluded by the authors that the nominal stress method is non-conservative while effective notch stress method is conservative compare with the experiments. LEFM was not part of the study.

Limited studies have used LEFM to evaluate the fatigue strength and life of large welded structures [5, 6, 10, 15, 16]. In the current study, a box-shaped welded structure corresponding to a common joint in a lifting equipment is evaluated. The following aspects were evaluated.

- $\quad$ LEFM is used to estimate the fatigue strength of a boxshaped-welded structure, which is a complex structure consisting of 12 major welds. The box-shaped-welded structures were tested in fatigue, strains were measured, and 10 data points were generated to add to the scientific database of component-level fatigue testing.

- Contrary to other methods such as effective notch stress method, which are limited to throughout the length cracks, LEFM can also be used for evaluating the fatigue life of intermediate, i.e., semi-throughout the length crack. Therefore, LEFM is used to evaluate the fatigue strength of a box-welded structure and estimations of fatigue life with LEFM are compared with the fatigue strength evaluations by nominal stress and effective notch stress methods [14]. It was found that LEFM is the best method to evaluate the fatigue strength of box-welded structure. Effective notch stress is too conservative while fatigue life estimations by nominal stress method were on the unsafe side.

- The effect of weld metal penetration, thickness of plates (e.g., flanges and webs) and load position (e.g., centric or eccentric) on fatigue strength of the welded box-shaped structures are studied. It was found that the fatigue strength of the box-shaped structure increases with the increase in weld metal penetration and increase in the thicknesses of flange and web plates, while eccentric loading leads to a reduction of fatigue strength.

- A commercial software, FRANC3D, is used in conjunction with ANSYS to simulate the propagation of semielliptical cracks as LOP defects in the circumferential weld root of the box-welded structures.

\section{Box-welded structure}

The box-welded structure is composed of two flanges and four web plates as shown in Fig. 1. The flanges are made of S700QL while the webs are made of S600MC [14]. Prior to welding, the plates were tack welded together at the corner and subsequently grinded. These plates are connected by longitudinal and circumferential bevel welds. The critical bevel weld subjected to fatigue (circumferential weld) is completed manually in five passes with Metal Active Gas (MAG) process. More information about weld dimensions and welding procedure can be found in [17].

Various cases of the box-welded structures are studied. The six cases considered are tabulated in Table 1 (MTA to MTF). MTA is a reference case with flange thickness of $30 \mathrm{~mm}$, web thickness of $10 \mathrm{~mm}$, and load applied in a centric position. Centric is when the load is applied in the middle of both flanges while the eccentric is applied $30 \mathrm{~mm}$ off-center. In these cases, the thicknesses of flanges and webs are varied to study their effect on fatigue strength.

\section{Experiments}

Experiments on box-welded structures are performed in the following four steps to provide input for LEFM calculations and verify the fatigue life estimations.

\subsection{Temperature and residual stress measurements}

Residual stresses due to the welding process can significantly affect the fatigue behavior. In general, compressive residual stresses are beneficial from fatigue point of view and tensile residual stresses are detrimental. For an accurate fatigue assessment, it is necessary to know the welding induced residual stresses $[1,6,10]$. The residual stress state and temperature 
a)

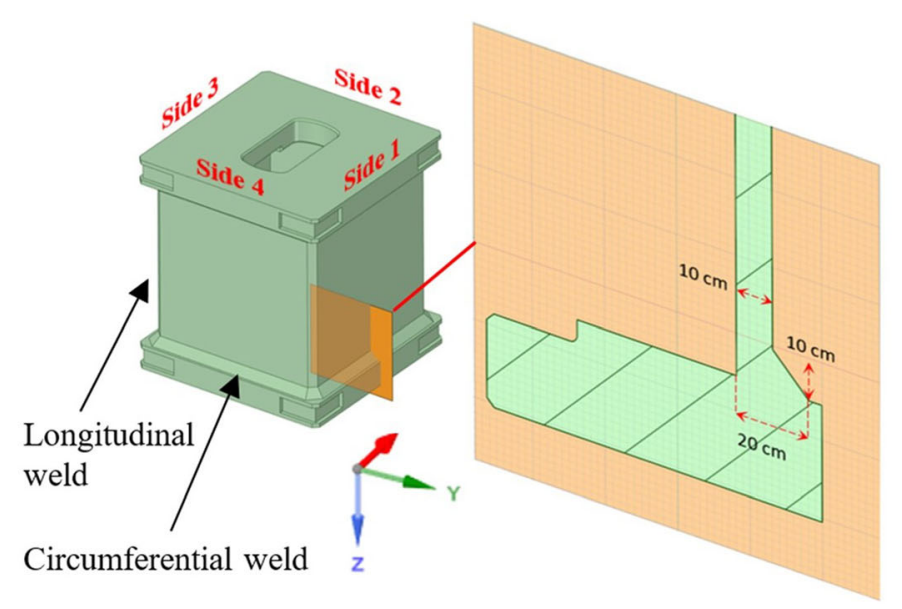

b)
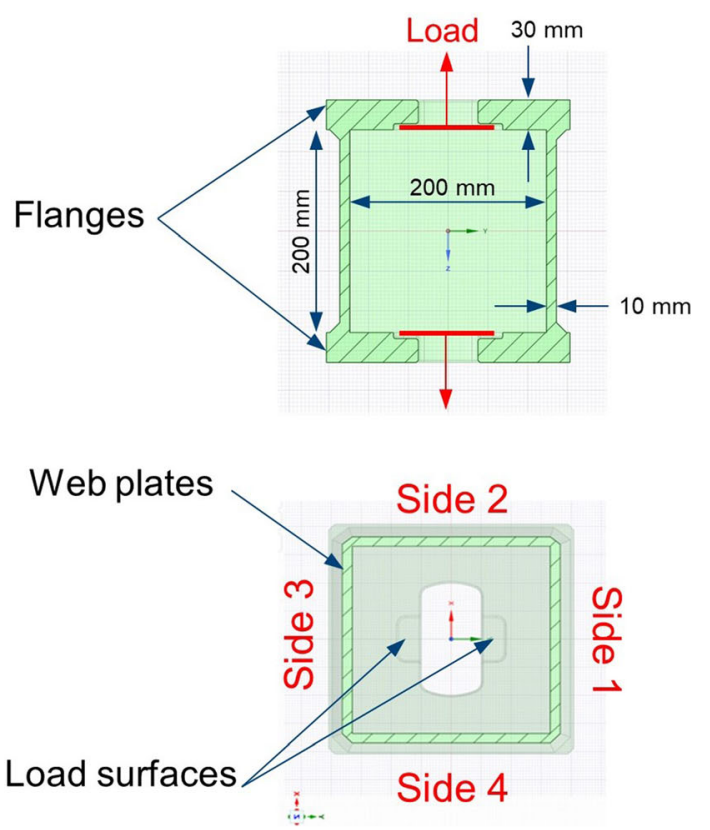

Fig. 1 a Box-welded structure. b Applied load and dimensions [14]

measurements in box-welded structure MTA case in this study were investigated in a previous study by Zhu et al. [17] experimentally and numerically. It was shown by Zhu et al. [17] that the difference between the estimated residual stresses (normal to the weld direction) from the fully penetrated and partially penetrated welds is small. For partial penetration case, a compressive residual stress of $-45 \mathrm{MPa}$ was estimated near the weld root while small tensile residual stresses were found for full penetration. These residual stresses were measured $1 \mathrm{~mm}$ below the surface due to length of the element being set to $2 \mathrm{~mm}$ in the numerical analysis by Zhu et al. [17].

\subsection{Fatigue testing}

The fatigue tests on the MTA structures were conducted at a stress ratio 0.03 and frequency of $0.25 \mathrm{~Hz}$. Four box specimens were tested in series at the same time. Strain gauges were mounted on the structure to monitor the applied load.

Table 1 Different box-shaped structure geometries for parametric studies

\begin{tabular}{llllll}
\hline $\begin{array}{l}\text { Specimen } \\
\text { Group }\end{array}$ & $\begin{array}{l}\text { Specimen } \\
\text { sketch }\end{array}$ & $\begin{array}{l}\text { Specimen } \\
\text { type }\end{array}$ & $\begin{array}{l}\text { Flange } \\
\text { thickness* }\end{array}$ & $\begin{array}{l}\text { Web } \\
\text { Thickness* }\end{array}$ & $\begin{array}{l}\text { Loading } \\
\text { mode }\end{array}$ \\
\hline $\begin{array}{l}\text { Reference } \\
\text { box }\end{array}$ & MTA & 30 & 10 & Centric \\
\hline $\begin{array}{l}\text { Dlange } \\
\text { thickness }\end{array}$ & MTC & 40 & 10 & Centric \\
\hline $\begin{array}{l}\text { Different } \\
\text { Web } \\
\text { thickness }\end{array}$ & MTC & 60 & 10 & Centric \\
\hline $\begin{array}{l}\text { Different } \\
\text { Hole } \\
\text { position }\end{array}$ & & 30 & 8 & Centric \\
\hline
\end{tabular}

*Dimensions in [mm] 
More information about the fatigue test configuration and equivalent load can be found in [14]. Additional experiments were conducted in the current study with a higher load in comparison to [14]. The fatigue test results are summarized in Table 2. Figure $2 \mathrm{a}$ shows that the structure fractured from circumferential weld with the fracture surface remaining normal to the loading direction.

*Equivalent load $F_{e q}(\mathrm{kN})$

\subsection{Strain gauge measurements}

Strains were measured on the box-welded structures tested in [14]. The details can be found in Table 3. In this study, strain gauges were mounted on different sides of specimen A5-A7 to measure the strains as illustrated in Fig. 3a. The measured strains during fatigue tests related to four sides of specimen A5 and two sides of specimen A7 are illustrated in Fig. 3c and d. For specimen A5 and A7, the crack was observed starting at 554 and 650 kilocycles, respectively, and strains were observed to drop due to stiffness reduction. Complete rupture also occurs at the cycles listed in Table 2.

Table 2 Fatigue test results of reference box structure and equivalent load

\begin{tabular}{lcc}
\hline Box specimen & Load $(\mathrm{kN})$ & Total cycles before rupture \\
\hline Test results from [14] & & \\
A1 & $225.994^{*}$ & $1,184,597$ \\
A2 & $227.919^{*}$ & $1,238,020$ \\
A3 & $223.870^{*}$ & $1,131,665$ \\
A4 & $230.294^{*}$ & $1,312,098$ \\
Average & $227^{*}$ & $1,216,595$ \\
St. dev. & $2.74^{*}$ & 77,065 \\
Test results from the current study & \\
A5 & 305 & 889,653 \\
A6 & 305 & 553,333 \\
A7 & 305 & 819,717 \\
A8 & 305 & $1,142,496$ \\
A9 & 305 & 536,282 \\
A10 & 305 & 646,037 \\
A11 & 305 & $1,248,538$ \\
A12 & 305 & $1,407,901$ \\
A13 & 305 & 334,258 \\
A14 & 305 & $1,080,924$ \\
Average & & 865,914 \\
St. dev. & & 350,070 \\
\hline
\end{tabular}

\subsection{Macrographs}

Macrographs of a manufactured reference box structure were prepared before fatigue testing in order to estimate the type, shape, and size of predominant imperfections [14]. The macrographs showed a significant LOP in some sections of the weld root while a complete root penetration is revealed in other regions; see Fig. 2b and c. The average LOP of $4 \mathrm{~mm}$ is therefore used as an initial condition for fatigue assessment of partial penetration case.

The macrographic examination was also carried out on a fractured specimen to determine the FCP behavior. For this purpose, the critical side of the specimen near the applied load was cut apart by portable flame cutting method. It is worth mentioning that the semi-elliptical profile of the crack surface can be clearly seen in Fig. 2 d. The remaining part was then separated to five equal spaced pieces using cutting band saw machine. In Fig. 2e, the cutting lines show where the section of each of the parts. Finally, the macrographic examination of the weld cross section at each part was made, with grinding and polishing to $3 \mu \mathrm{m}$ diamond size followed by etching with $4 \%$ Nital.

In Fig. 2f, the macrographs taken from these cross sections of the weld are shown. Generally, it is observed that the crack starts to propagate form the root due to high stresses located at the crack tip of LOP and it inclines toward the HAZ due to microstructural changes, which has inherently a lower strength and resistance to cracking. Thereafter, it continues to propagate in a planar fashion without any significant inclination, until the remaining ligament cannot withhold the applied load and final rupture occurs. Therefore, simulation of box-welded structure under constant amplitude cyclic loading, the assumption of straight and co-planar crack growth is acceptable throughout $75 \%$ of the total thickness.

\section{Finite element analysis}

Finite element analysis (FEA) is performed on the box structure with the use of the software Spaceclaim for solid modeling and ANSYS workbench to establish the maximum stresses and deflections. The actual weld bead geometry according to macrographs in Section 3.4 is modeled. The width and length of the weld are illustrated in Fig. 1a where the side plates (web plates) are numbered from one to four.

Tetrahedral elements with a global element size of $5 \mathrm{~mm}$ are used to mesh the model. The meshing at welded region of interest (the most prone region for fatigue) is refined with ratio of three to capture the stresses and strains more accurately. It is assumed that both sides of the weld will experience similar stresses during testing; therefore, the upper part of the box structure is fixed from the cutout notch. The weld near this location is not analyzed. A distributed load is applied as 
Fig. 2 a Fatigue failure position in specimen A3. b Partial penetration. c Full penetration. d Semi-elliptical crack surface on critical side of A1 specimen. e Cutting lines on critical side of A2 specimen. f Macros of cutting cross section

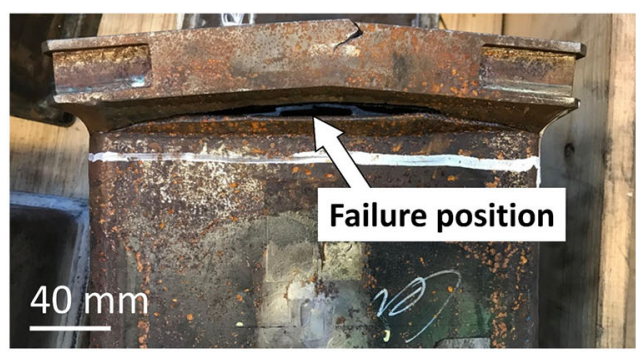

(a)

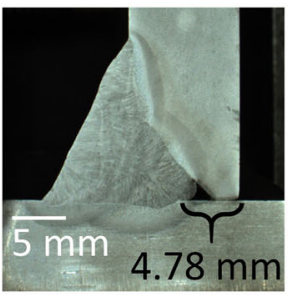

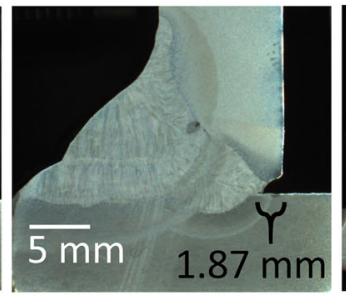

(b)

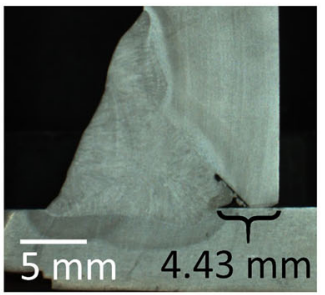

$5 \mathrm{~mm} \quad 4.43 \mathrm{~mm}$

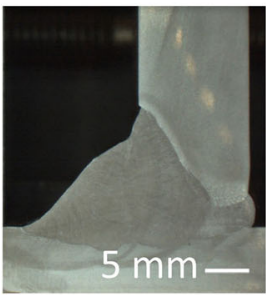

(c)

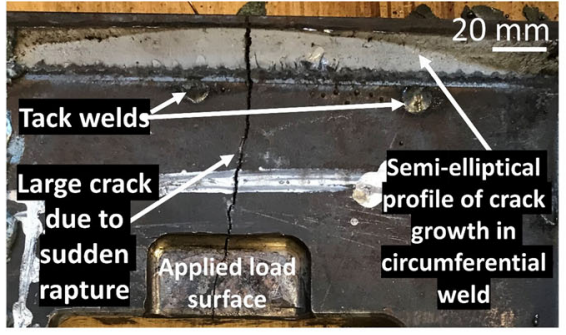

(d)

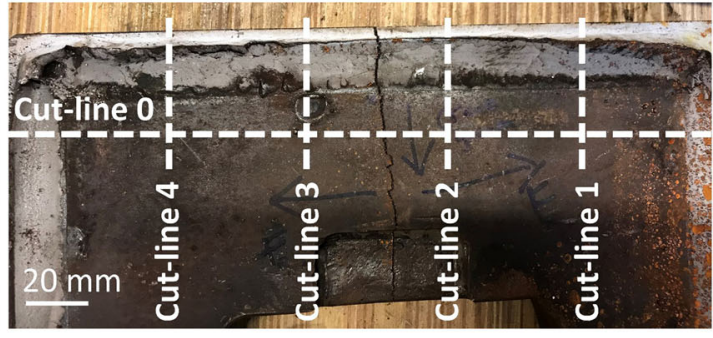

(e)

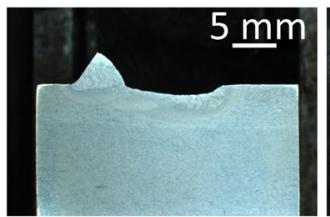

Cut-line 1

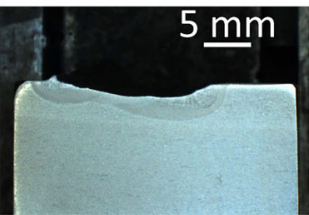

Cut-line 2

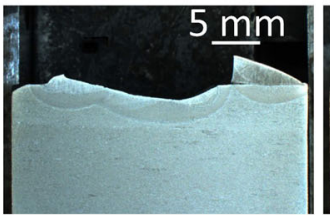

Cut-line 3

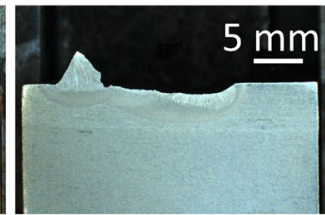

Cut-line 4

(f)

shown in Fig. 1b. A magnitude of $227 \mathrm{kN}$ was applied based on the calculated average equivalent load $F_{e q}$ in [14]. For the specimens in this study, a force of $305 \mathrm{kN}$ was applied.

The stress contour plots from the global stress analysis are shown in Fig. 4. It was observed that the von-Mises stresses have approximately the same magnitude as the 1st principal stress. This indicates that multi-axial stresses are not present and could be disregarded in further analysis. The estimated critical location for crack propagation is on the weld root based on higher magnitude of 1st principal stresses observed in the FEA.

The strain values at the center of the web plates were determined using FEA. Strain value from FEA is compared with both experimentally measured strains and previous FEM results [14] as shown in Fig. 3b and Table 3. This strain evaluation shows that the agreement between the FEA results and actual testing is rather good, which confirms the validity of the FEA model built-in Ansys.

\section{Linear elastic fracture mechanics}

\subsection{Modeling of weld root defects and initial conditions}

In order to simulate the crack propagation using linear elastic fracture mechanics (LEFM) and evaluate the fatigue life of the box structure, an initial semi-elliptical surface crack was introduced into the weld root in accordance with the macrographs. LEFM was conducted for four cases tabulated 
Table 3 Comparison of strains from FEA with experiments

Normal elastic strain in $\mathrm{Z}$ direction $[\mu \mathrm{m} / \mathrm{mm}]$

Average equivalent load, $F_{e q}=227 \mathrm{kN}$

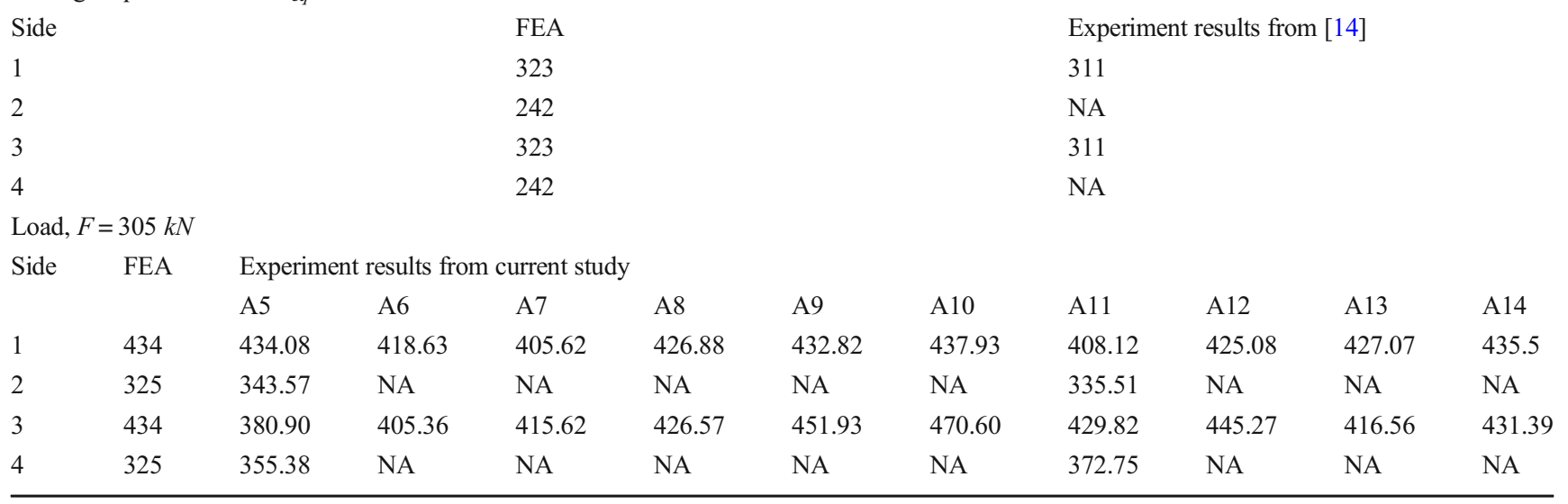

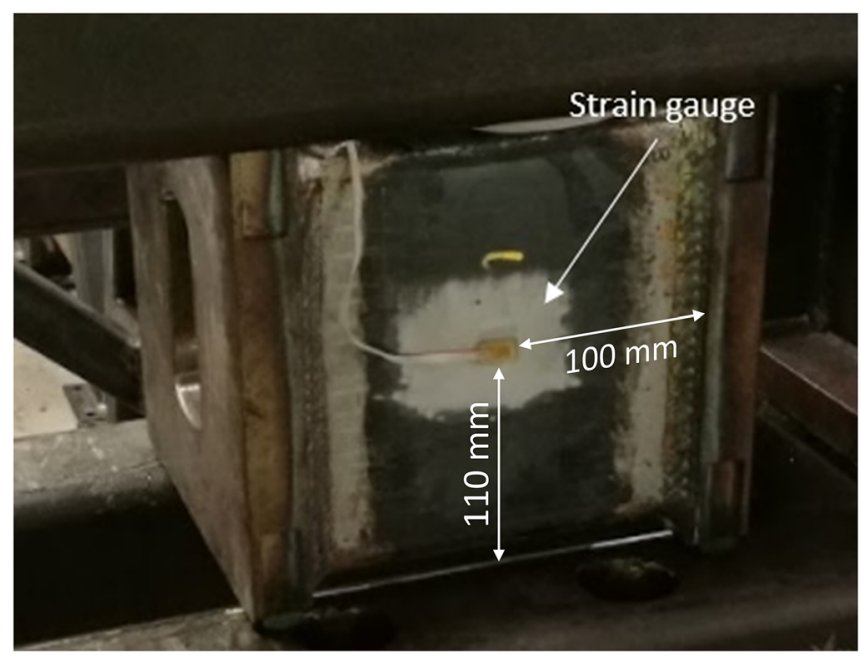

(a)

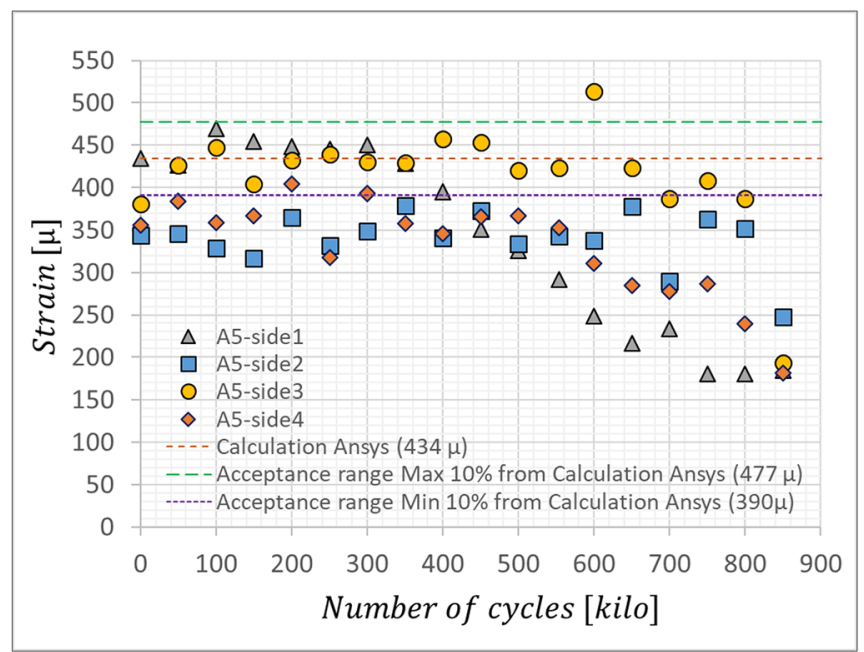

(c)

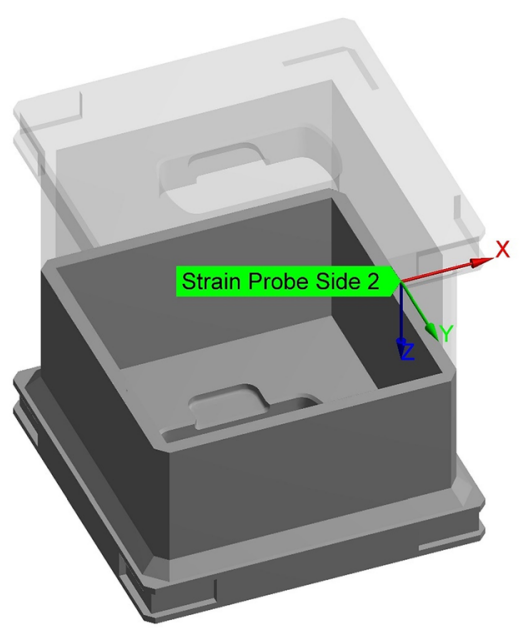

(b)

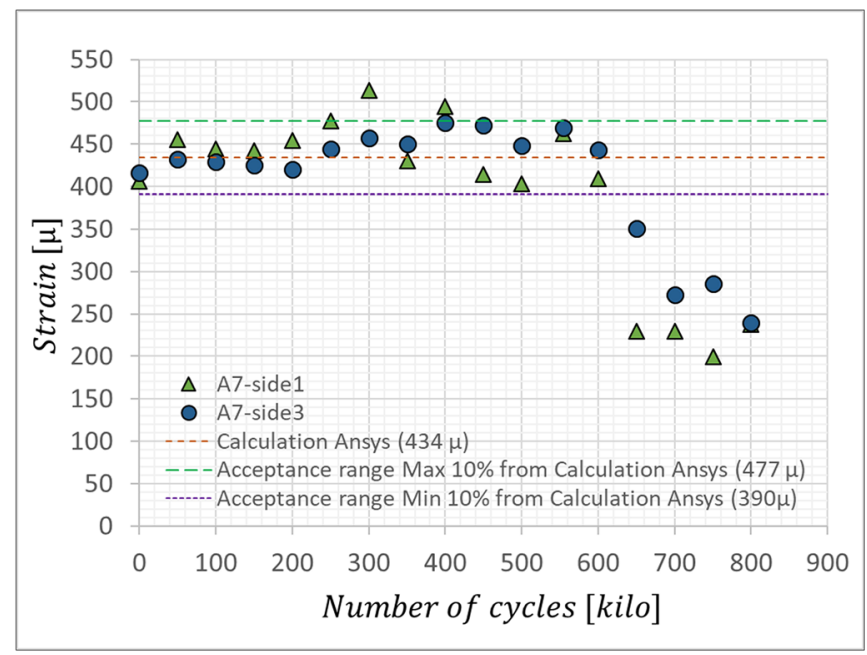

(d)

Fig. 3 a Position of strain gauges in experiment. b Position of strain gauges in FE-Model. c Strain changes during fatigue testing for specimen A5. d Strain changes during fatigue testing for specimen A7 


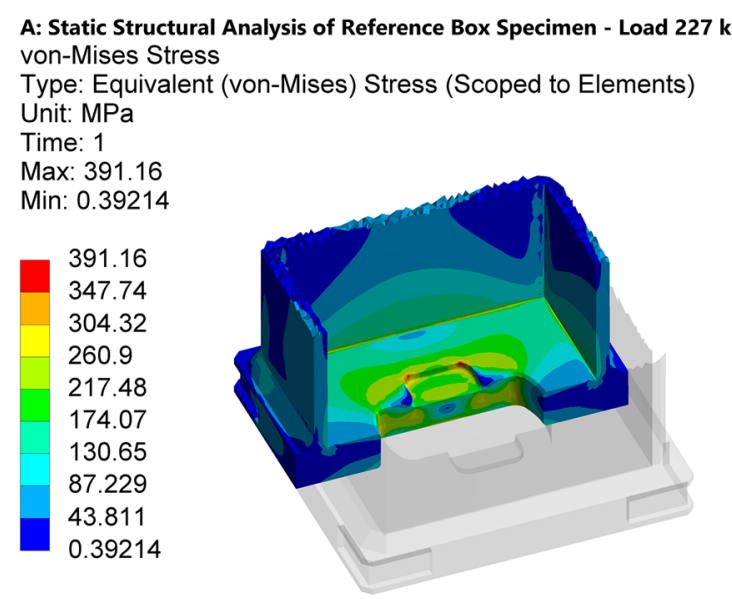

(a)

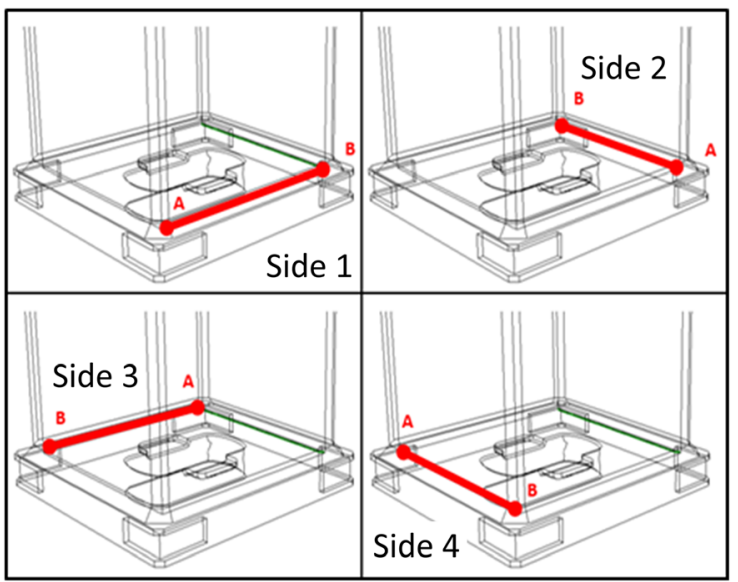

(c)
A: Static Structural Analysis of Reference Box Specimen - Load 227 kN 1st Principal Stress

Type: Maximum Principal Stress (Scoped to Elements) Unit: MPa

Time: 1

Max: 449.64

Min: -116.23

449.64
386.76
323.89
261.02
198.14
135.27
72.395
9.5216
-53.352
-116.23

$-116.23$

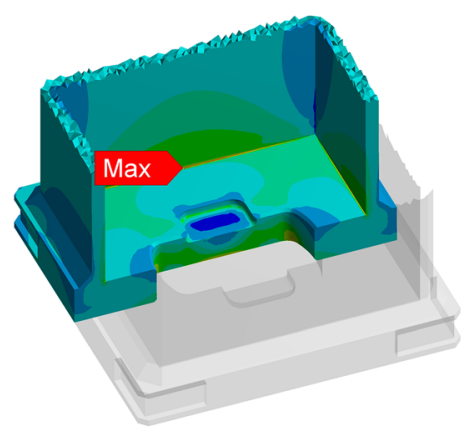

(b)

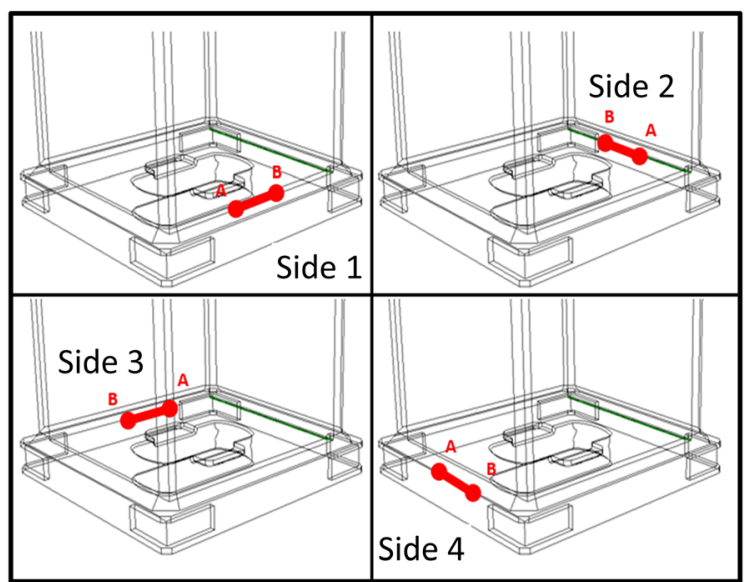

(d)

Fig. 4 FEA results. a Equivalent von-Mises stress. b Maximum (1st) principal stress. c Position of full-length crack in the model. d Position of intermediate crack in the model

in Table 4 based on the definition of crack to simulate full penetration and partial penetration welds. For partial penetration case, a crack depth of $4 \mathrm{~mm}$ was chosen based on the observation (see Section 3.4), whereas this size was decreased to an arbitrary value of $0.5 \mathrm{~mm}$ when the full penetration case is considered. Moreover, two different crack widths were taken into account, a full-length and an intermediate crack. The full-length crack represents the situation when the LOP exists along the entire length of the weld (i.e., the most conservative

Table 4 Initial crack specifications

\begin{tabular}{llll}
\hline Case & Crack profile & Depth $(\mathrm{mm})$ & Width $(\mathrm{mm})$ \\
\hline 1 & Full-length, partial penetration & 4 & $\approx 198$ \\
2 & Intermediate, partial penetration & 4 & 40 \\
3 & Full-length, full penetration & 0.5 & $\approx 198$ \\
4 & Intermediate, full penetration & 0.5 & 40 \\
\hline
\end{tabular}

case), while the intermediate (or intermittent) crack represents insufficient penetration only in the small section of the weld line (i.e., the most common case in practice).

\subsection{Paris law}

The well-known Paris equation [3] for fatigue assessment based on LEFM is expressed by:

$$
\frac{d a}{d N}=C \Delta K^{m}
$$

where the two material constants of $C$ and $m$ are determined experimentally [18]. In Eq. (5.1), the fatigue crack growth rate $d a / d N$ depends only on stress intensity range $\Delta K$ and is not sensitive to the R-ratio or crack closure. However, both the environment and the applied stress ratio $R$ may have a strong effect on $C$ and $m$. In the current study, these parameters were based on the recommendations given by IIW [1] for steels; see Table 5. 
The residual fatigue life can be directly estimated by integrating Paris' law:

$N=\int_{a_{0}}^{a_{f}} \frac{d a}{C \Delta K^{m}}$

In Eq. (5.2), there are four unknown variables including initial crack $a_{0}$ size, final or critical crack size $a_{f}$, stress intensity range $\Delta K$ and the number of cycles $N$ for a crack growth from $a_{0}$ to $a_{f}$. If any three of these parameters are known, then equation can be used to calculate the fourth parameter.

\subsubsection{Stress intensity range}

It has been observed that the strain energy release rate [19] and stress intensity [20] approaches, which describe the crack conditions in LEFM, are essentially equivalent for linear elastic materials. There are a variety of direct and indirect methods available for calculating the energy release rate and stress intensity factors in both $2 \mathrm{D}$ and 3D. In this study, FRANC3D is used to compute SIFs based on the M-Integral method due to its high accuracy $[21,22]$.

\subsubsection{Mean stress effect (R-ratio)}

In the region where the power law applies, there is no influence of the R-ratio and the rate of crack propagation depends entirely on the stress intensity factor range. However, at both high and very low values of $\Delta K$, crack propagation rate depends on the mean stress $[6,16,23]$. Hence, to determine the threshold stress intensity factor and fracture toughness measured experimentally, one should consider the effect of Rratio. The R-ratio in the box structure studied here is 0.03 .

\subsubsection{Threshold SIF}

There is a critical value of stress intensity factor below which fatigue crack growth does not occur. This is known as the fatigue threshold which indicates the material resistance to crack propagation $[1,6,24]$. The threshold stress intensity factor range for as-welded steel structural components given in [4] is used in this study. For R-ratio of 0.03, the threshold value is $163.58 \mathrm{MPa} \sqrt{ } \mathrm{mm}$. It is noted that experimental investigation on different grades of steel show that all the examined steels could be represented by the same $\Delta K_{t h}$ value [25].

\subsubsection{Crack closure}

The concept of crack closure proposed by Elber [26] consists of introducing an effective stress intensity factor range into the Paris' law. Elber postulated that crack closure decreases the fatigue crack growth rate by reducing the effective stress intensity range and proposes an effective stress-intensity range $\Delta K_{\text {eff }}$ in a modified Paris equation. In this study, the influence of crack closure caused by cyclic loading has not been taken into account due to (1) the estimated small magnitude of residual stresses at weld root $(-45 \mathrm{MPa})$, due to $(2)$ the expected redistribution of residual stresses with fatigue crack growth and subsequent relaxation of these compressive residual stresses. This assumption might result in less accurate life estimations but they will be on conservative side as compressive residual stresses at the weld root for large structures have shown beneficial effect on the fatigue life [10]. If the magnitude of compressive residual stresses was high at the weld root or the cracks would initiate at the weld toe taking into account the type of external loading. The effect of cracks closure effects or compressive residual stresses would have to be included. For further information about inclusion of compressive residual stresses and crack closure effects, the readers are referred to $[10,15,16,24,27]$. The effective stress intensity factor for box-welded structure in this study is defined as follows:

$\Delta K_{e f f}=K_{\max }-\max \left(0, K_{\min }\right)$

\subsubsection{Initial crack size}

In welded structures, existence of sharp flaws may act as starters for fatigue crack growth and thus the crack initiation phase is negligible [13]. Furthermore, the behavior of short cracks is not considered in this study as technically no short cracks exists in the manufactured specimens (LOP $4 \mathrm{~mm}$ ). Generally, it has been shown that microstructurally and physically small cracks have higher fatigue crack growth rates in comparison to long cracks, which shifts the fatigue crack growth curve in region I to the left in comparison to long crack fatigue crack growth curve [24]. For further information about short cracks and their behavior, readers are referred to literature $[6,15,24,27,28]$. In box-welded structures, the actual root gap due to LOP, i.e., $4 \mathrm{~mm}$ can be used as the initial crack $a_{0}[4,9]$; see Section 5.1.

Table 5 Parameters of the Paris power law for steels [1, 10]

\begin{tabular}{lll}
\hline Paris' Law parameters & $95 \%$ Survival probability & $50 \%$ Survival probability \\
\hline$C[\mathrm{MPa} \sqrt{\mathrm{mm}}]$ & $5.21 \times 10^{-13}$ & $1.5 \times 10^{-13}$ \\
$m$ & 3 & 3 \\
\hline
\end{tabular}




\subsubsection{Critical crack size}

The final crack size in this study does not follow the criterion given in $[1,29]$. Instead, the critical crack size corresponding to $75 \%$ of total thickness has been used in the fatigue life calculation, since the crack propagates with the reduced crack growth rate in the direction of web thickness. Moreover, available fatigue test results and the macrographs taken from the weld after rupture show that assuming this critical crack size is reasonable.

\subsection{LEFM analysis process}

The global FE model described in Section 4 was used for the fracture mechanics analysis of the critical welds. The boundary conditions and load were applied in ANSYS and was subsequently imported to FRANC3D to describe the crack. In order to reduce the CPU time, the un-cracked model was divided into global and local models without changing the mesh density. It is important that the sub-model is large enough such that the transition of the mesh between the global and local model is smooth. After inserting the initial crack and re-meshing the sub-model, the displacements from the static analysis were imported to FRANC3D where the SIFs are calculated. These SIFs were needed to estimate the direction and amount of crack propagation along the crack front points [30]. This process includes re-meshing the local model and computing the displacements, was repeated until the final crack size is achieved.

It should be noted that FRANC3D v7.3 [4] utilized in this study was not able to handle the case with a portion of the crack surface being coincident with the model surface. Likewise, it has serious difficulties to mesh the crack-front when it intersects one of the corners in the model. Therefore, in order to overcome these two shortcomings, first, the width of full-length crack was selected somewhat shorter than the weld line to avoid the corners. Second, all initial cracks were introduced into the weld root at a distance of $1 \mathrm{~mm}$ from the edge.

\subsection{Identification critical side in box welded structure}

Prior to crack propagation, the initial SIFs were computed to find the critical side which may lead to the fatigue failure. In this regard, all types of cracks defined in Section 5.1 were inserted into different sides of the model (see Fig. 4c and d) and the SIFs in all modes were calculated according to the procedures outlined in Section 5.3. Figure $5 \mathrm{a}$ and $\mathrm{b}$ show the SIFs along the entire normalized crack front distance for case 1 (full-length, $4 \mathrm{~mm} \mathrm{LOP}$ ) for various sides of the box structure. It should be noted that only the results for side 1 and 2 are plotted, since similar results were obtained for the opposite sides due to symmetry.
The SIFs results show high value in the first mode $K_{I}$ which are far above the threshold values. The SIF in opening mode is high at the middle and tends to decrease close towards the corners of the structure due to higher stiffness and constraints. This trend indicates that the growth is expected at the center of the joint with a moderate rate. It can also be seen that $K_{I I}$ (shearing mode) and $K_{I I I}$ (tearing mode) compared to $K_{I}$ are negligible and below the threshold value $\Delta K_{t h}$, especially at the center of the crack. Hence, a mixed-mode crack growth can be disregarded and the co-planar crack propagation is a valid assumption. In addition, comparison of $\Delta K_{I}$ in different sides of the structure shows the highest SIF in side 1 (or side 3 ) close to the load application area; see Fig. 5c. Higher crack growth rate is therefore expected from this critical side.

The FM analysis result related to initial condition of crack case 2 (intermediate, $4 \mathrm{~mm}$ LOP), including calculated SIFs and their comparisons, are plotted in Fig. $5 \mathrm{~d}$ to e. In this case, the intermediate crack width of $40 \mathrm{~mm}$ was inserted into the middle of the weld where the highest peak SIFs is close to the load surfaces. The same conclusions as for case 1 were reached about critical sides and dominated mode I loading. However, it is observed that $K_{I}$ at the corners is much higher than the threshold value and it does not decrease significantly compared to the center of the crack.

The LOP of $0.5 \mathrm{~mm}$ was used in order to simulate a case as close as possible to a full penetration. Accordingly, the crack case 3 and 4 were inserted into the different sides of the model and the stress intensity factors in all modes were calculated. The SIFs throughout of such cracks are compared with the partial penetration case in Fig. $5 \mathrm{~g}$ and $\mathrm{h}$. The result shows lower values along the crack front for LOP of $0.5 \mathrm{~mm}$ which can lead to considerably slower crack growth. Furthermore, the calculated SIFs for full penetration indicate that $K_{I}$ in some sections close to the corners is slightly below the threshold value.

\subsection{Crack propagation}

The crack growth analysis was carried out bearing in mind that the circumferential weld in side 1 (or side 3 ) is the critical one among all four exposed to fatigue loading. Therefore, cracks inserted to this side are propagated through an incremental procedure handled by FRANC3D [30].

\subsubsection{Mixed-mode growth}

Under mixed-mode loading conditions, a crack extends in a non-coplanar manner and its propagation direction is changed. There are several different criteria to calculate the direction. One of the most widely used mixed-mode criteria is the maximum tensile stress criterion (MTS) proposed by Erdogan and Sih [31], which is used in this study. In the FCP analyses, there are two common approaches for estimation of equivalent 


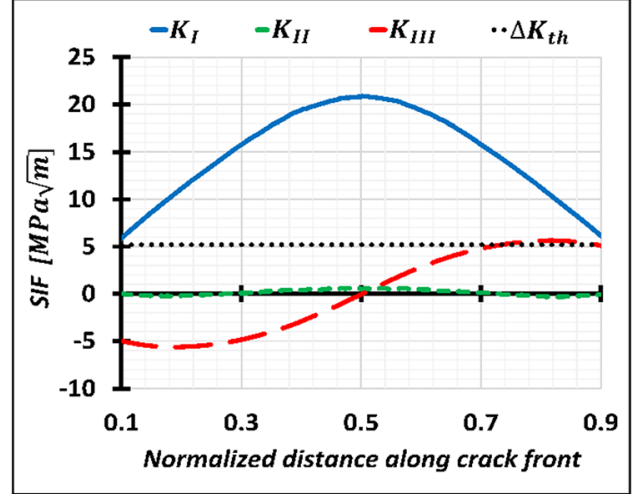

(a)

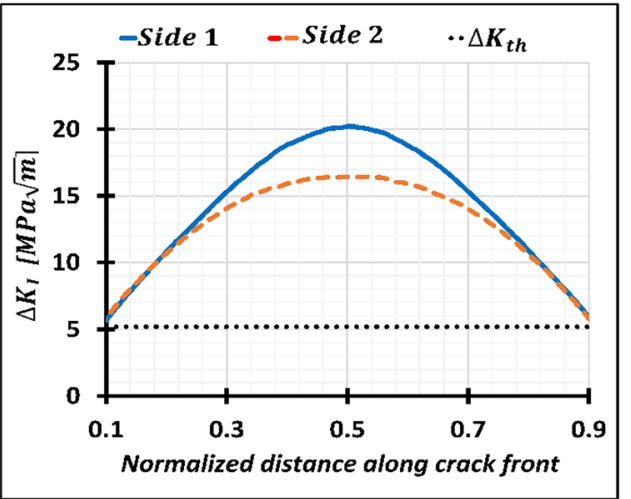

(c)

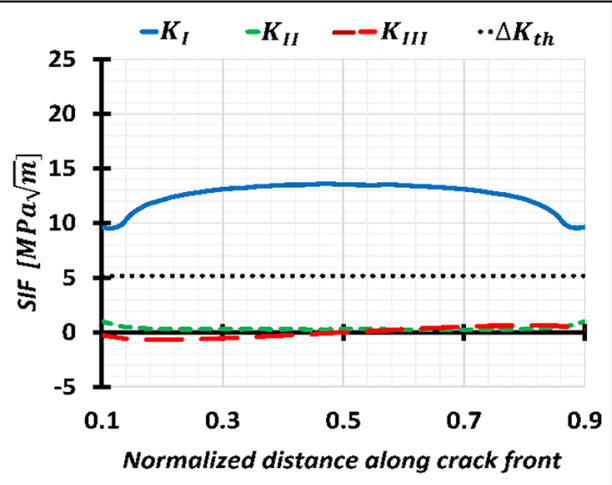

(e)

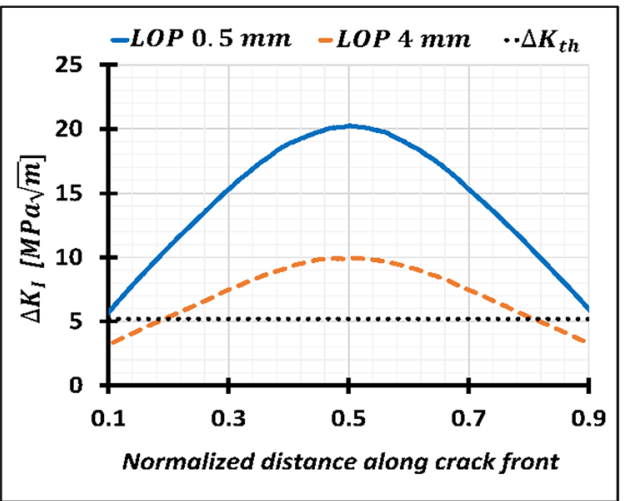

(g)

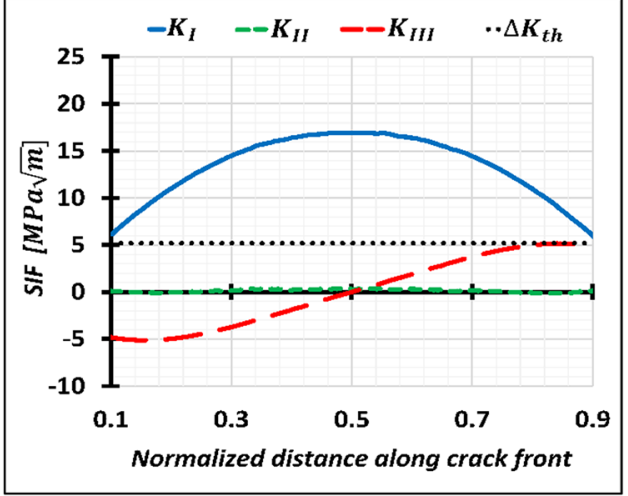

(b)

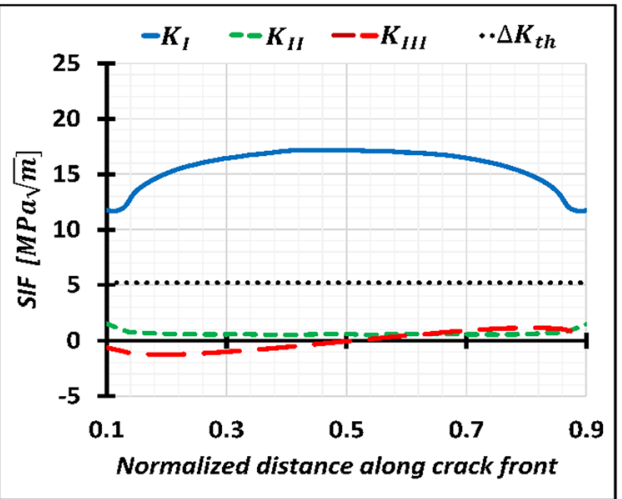

(d)

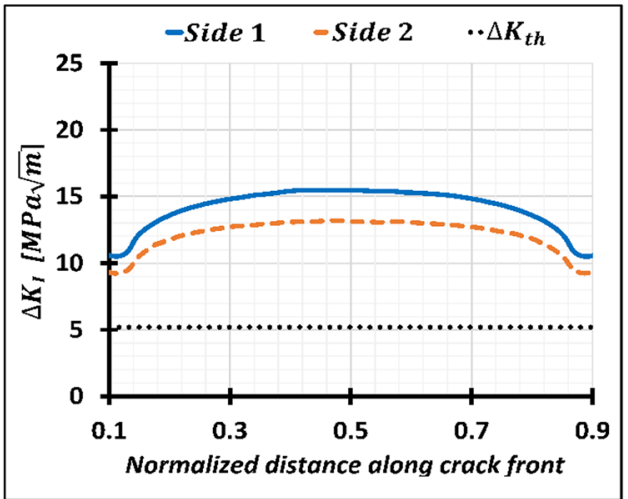

(f)

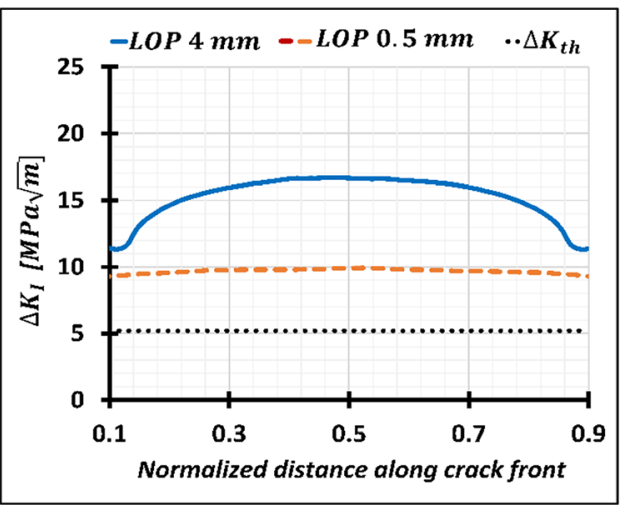

(h) 
Fig. 5 a SIFs along the initial crack case 1 in Side 1 . b SIFs along the initial crack case 1 in Side 2. c Comparison of opening mode $\Delta K_{I}$ along the crack case 1 in different sides. d SIFs along the initial crack case 2 in Side 1. e SIFs along the initial crack case 2 in Side 2. f Comparison of opening mode $\Delta K_{I}$ along the crack case 2 in different sides. $\mathbf{g}$ Comparison of $\Delta K_{I}$ along the crack case 3 (full penetration) with case 1 (partial penetration) in critical side 1 . $\mathbf{h}$ Comparison of $\Delta K_{I}$ along the crack case 4 (full penetration) with case 2 (partial penetration) in critical side 1

stress intensity factor in mixed-mode condition, the dominant mode approach and combined modes approach [32]. According to dominant mode approach, SIF range in mode I $\left(\Delta K_{I}\right)$ is the governing crack opening mode and defined by Eq. (5.4), while in the combined modes approach, the equivalent SIF range $\left(\Delta K_{e q}\right)$ can be calculated based on one of mixed-mode criteria.

$\Delta K_{e q}=\Delta K_{I}$

As it can be observed in Fig. $6 \mathrm{a}$ and $\mathrm{b}$ for intermediate crack, $K_{I I}$ is much lower than $K_{I}$ and it becomes approximately zero just after one crack growth step $(0.1 \mathrm{~mm})$. Figure $6 \mathrm{c}$ also shows that the initial kink angle of -15 degrees in the middle of the crack suddenly drops down to zero for further increments. Hence, it can be an admissible assumption to implement the dominant mode approach using $K_{I}$ values and neglect the mixed-mode condition. It should be noted that in mixed-mode condition, crack extension was not feasible more than six steps due to large distortion of the crack at the ends and the intersection of the crack front with the edge; see Fig. $6 \mathrm{~d}$.

\subsubsection{Co-planar growth}

The crack propagation was assumed to be planar $(\theta=0)$, based on the low value of $K_{I I}$ and $K_{I I I}$ and distortion problem. The median extension of $0.5 \mathrm{~mm}$ was selected for each growth step since larger or smaller increment values might lead to inaccurate results or excessive increase of crack growth steps. It is noted that for full-length crack (cases 1 and 3), curve fitting was not possible due to meshing problems. Therefore, instead of using crack increment and the computed SIF values at the crack front points, SIFs history was built up by inserting a series of bigger cracks manually. Figure $6 \mathrm{e}$ and $\mathrm{f}$ show the dominated mode of SIF, $K_{I}$ along the crack front for the crack growth of case 3 and 4 (full penetration), respectively. Figure $6 \mathrm{~g}$ also shows the SIF along the path for $50 \%$ normalized distance in both full-length and intermediate cracks.PathIt can be seen from Fig. 6e and g, for full-length crack, the high values of SIF which result in the fastest crack growth rate centered in the area close to the load application surface. In the final steps of crack propagation when the crack has extended about $14 \mathrm{~mm}$ through the thickness, the SIFs slightly decrease. Moreover, due to higher stiffness and constraints, the SIFs are less pronounced at the corners compared to the middle.

In Fig. 6f, it can be observed that for the intermediate crack all the SIFs along the crack front are highly above the threshold value which indicates that crack growth occurs throughout the entire crack front. During the preliminary increments, the SIF tends to increase in the center where the higher crack growth appears. However, after a few steps of crack growth, it shows a completely opposite manner and the crack expands with the higher rate at the crack front edges.

\subsubsection{Fatigue life estimation}

The fatigue life is estimated using the unmodified version of Paris' law. The average number of cycles per crack step is calculated in FRANC3D using a multiple variable degrees of freedom (MVDF) approach [4]. In order not to overestimate the fatigue life, especially for the full-length cracks, the life is also calculated numerically in MATLAB based on SIF obtained at $50 \%$ normalized crack front distance.

The number of cycles is calculated using the $K_{I}$ SIF ranges in the depth direction where the other modus is negligible. The characteristic growth data $(C$ and $m)$ are taken from IIW recommendations [1] for failure probability of $2.3 \%$ and $50 \%$. These parameters are based on testing with the load ratio of 0.03 . Crack growth will only occur if the SIF range is above the threshold value [1, 24, 27]. Residual stress, mean stress effect, threshold effect, and unstable crack growth are neglected and only the crack propagation phase is assumed to be part of the fatigue life. The results are illustrated and tabulated in Fig. 7a and Table 6, respectively. As shown in Fig. 7a, the residual life of the box structure with the intermediate crack is greater than for the full-length crack state. Moreover, for equivalent load of $227 \mathrm{kN}$, the total number of cycles for intermediate crack with full penetration is 838,979 cycles whereas this value for $4 \mathrm{~mm}$ LOP decreases to 589,198 cycles, both with failure probability of $50 \%$. The correlation of life estimated for intermediate crack with LOP $4 \mathrm{~mm}$ at failure probability of $50 \%$ with the experiments is shown in Fig. 7c and d. The solid line in the figure shows when the fatigue life is estimated with $100 \%$ accuracy. It can be observed that the estimated life is on the safe side of the line. A high scatter can be seen in the tested life in this study. This can be partly connected to the scatter in measured LOP which varied between 3 and $5 \mathrm{~mm}$. However; the average was calculated to be around $4 \mathrm{~mm}$.

Based on the results in Table 6 and comparing the computed total number of cycles to failure (i.e., columns 5 or 6 ) with their averaged values (i.e., columns 7 or 8 in table), a little variation is found for the intermediate crack while a significant difference can be observed for the full-length crack, which is due to the MDVF approach in FRANC3D [4]. This discrepancy elucidates the inability of this approach to 


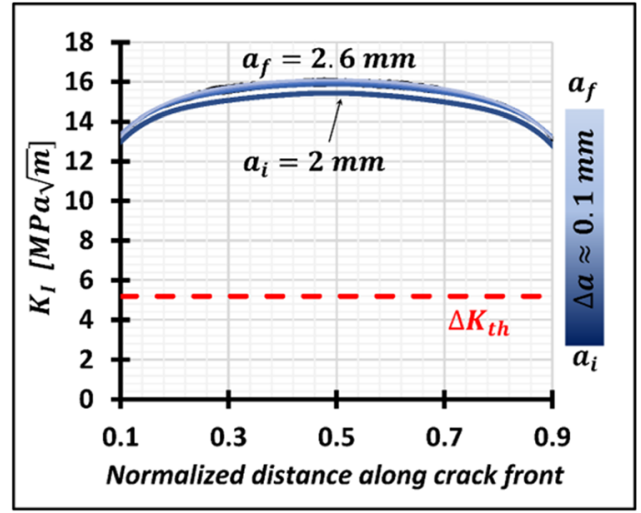

(a)

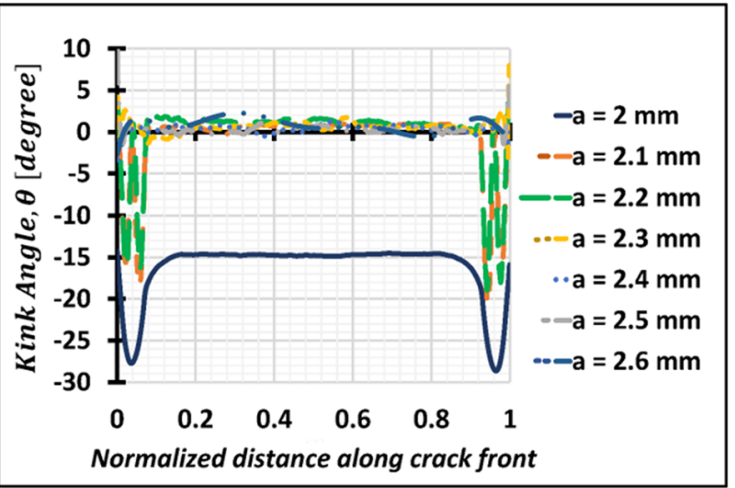

(c)

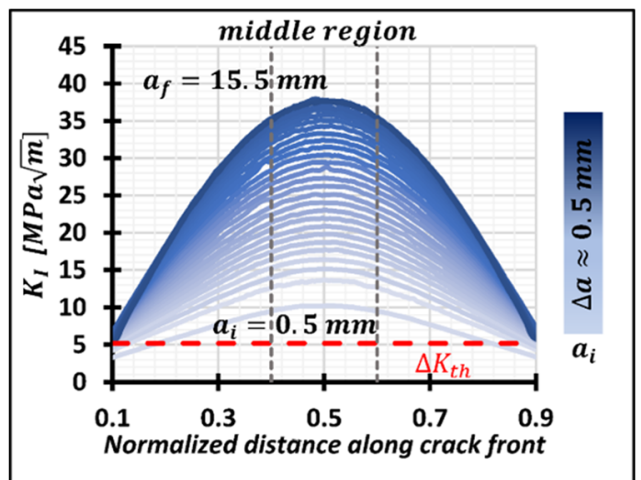

(e)

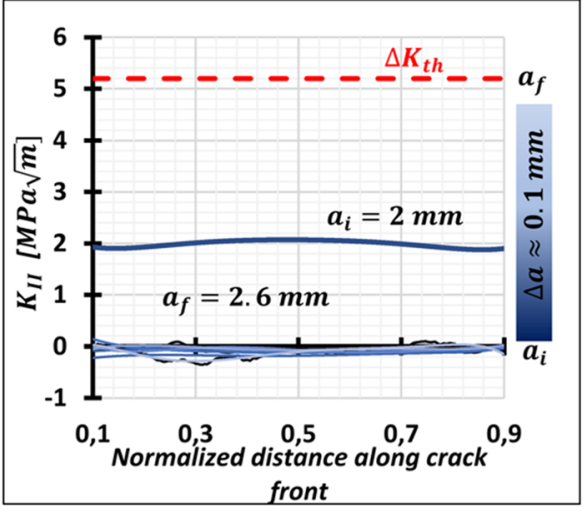

(b)
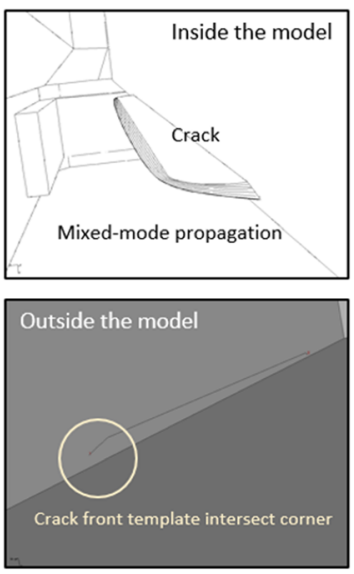

(d)

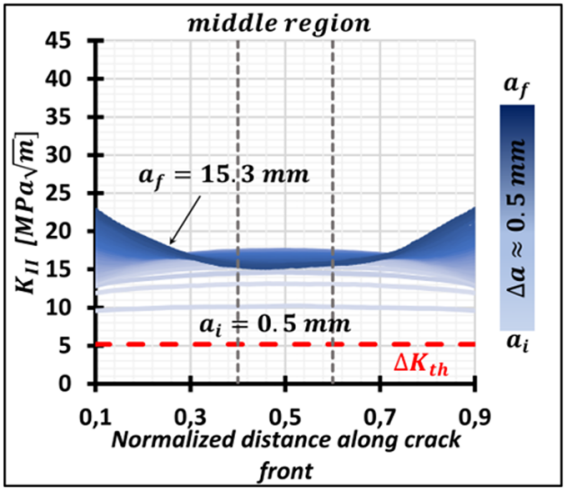

(f)

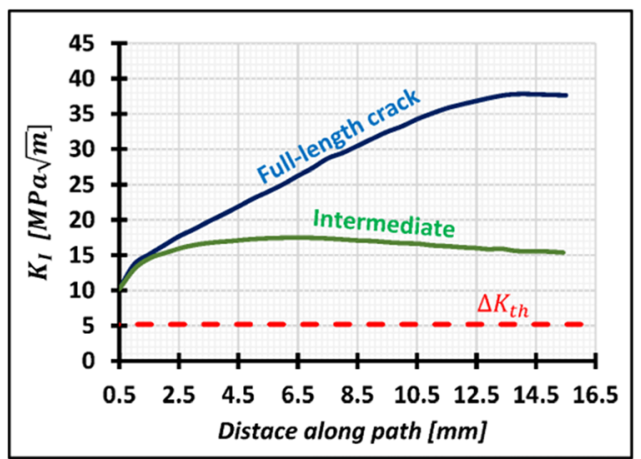

(g) 
Fig. 6 a $K_{I}$ and b $K_{I I}$ along intermediate crack front in mixed-mode condition. c Kink angle along intermediate crack front in mixed-mode condition during $0.6 \mathrm{~mm}$ extension. $\mathbf{d}$ Distortion in mixed-mode condition. e $K_{I}$ along crack front for the propagation of full-length crack. $\mathbf{f}$ $K_{I}$ along crack front for the propagation of intermediate crack. $\mathbf{g} K_{I}$ along the path for $50 \%$ normalized distance in full-length and intermediate cracks

evaluate the fatigue cycles for a long shallow crack despite its numerous benefits.

\section{Comparison of fatigue assessment methods}

The fatigue strength of the box structures has been evaluated based on IIW recommendation [1] using nominal and effective notch stress methods in [14]. Specimen type A and C in [14] correspond to the full and partial penetration cases, respectively, which have been investigated in this study. In Table 7 , the results for nominal and notch effective stress methods are summarized. It is noteworthy that the results were scaled with respect to the equivalent load range $\left(\Delta F_{e q}=\right.$ $227 \mathrm{kN}$ ) used in testing and LEFM approach [33] by:
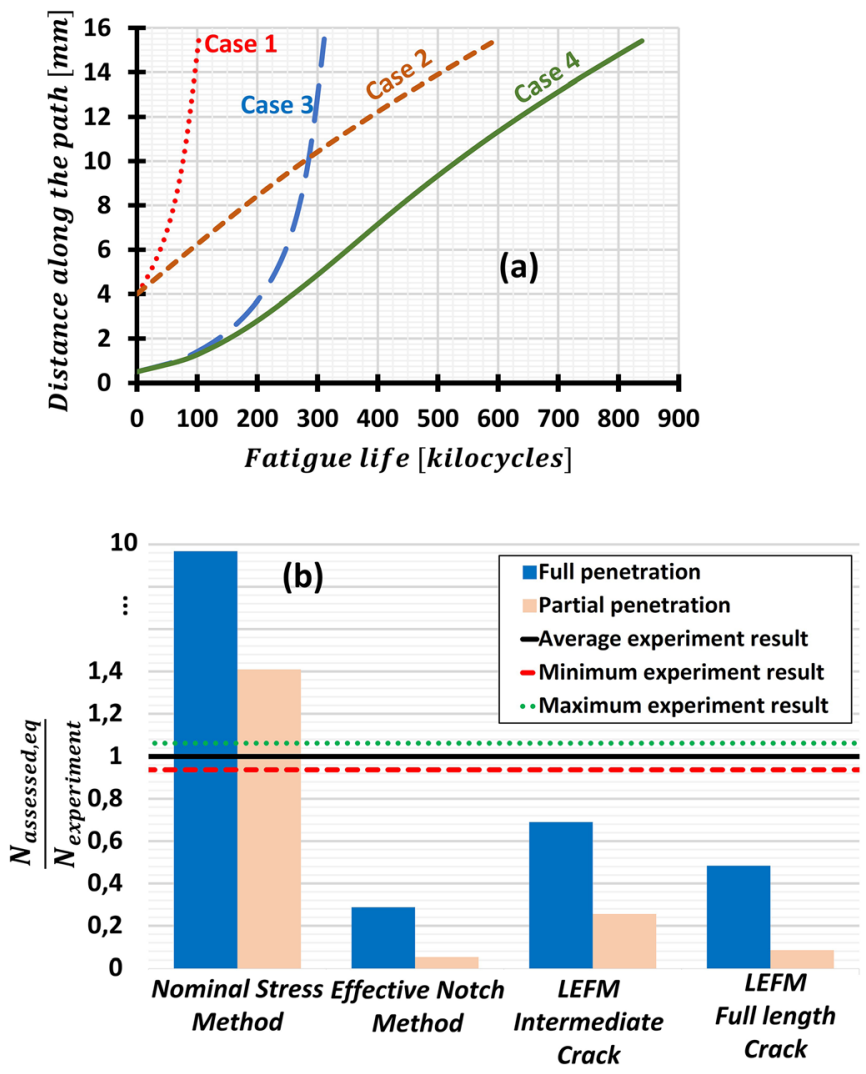

Fig. 7 a Number of cycles as a function of crack depth on the path for $50 \%$ normalized distance in the reference box specimen $\left(p_{f}=50 \%\right)$. b Comparison of fatigue assessment methods including LEFM with
$N_{\text {assessed }, e q}=N_{\text {assessed }}\left(\frac{\Delta F_{\text {assessed }}}{\Delta F_{e q}}\right)^{3}$

Figure $7 \mathrm{~b}$ depicts the comparison of local and global fatigue assessment methods with the experiment. It can be observed that the LEFM analysis could estimate the fatigue life of the box structures acceptably well in comparison to the experiments. Furthermore, comparing LEFM analysis of full-length crack with effective notch stress method shows that the results are close to each other for partial penetrated weld. The correlation between fatigue life from experiments and estimated fatigue life by various methods can be seen in Fig. 7c and d. It can be observed that the life estimated by nominal stress approach is on the unsafe side while those by effective notch stress and LEFM is on the safe side of the curve. Effective notch stress method is very conservative and estimating life of 63,385 cycles. Effective notch stress method has a limitation, i.e., a notch along the full length of the crack has to be modelled $[1,5,6]$. That might be the reason that life estimation with effective notch stress is too conservative because in box-welded structures intermediate LOP crack was more common. The life estimation by effective notch
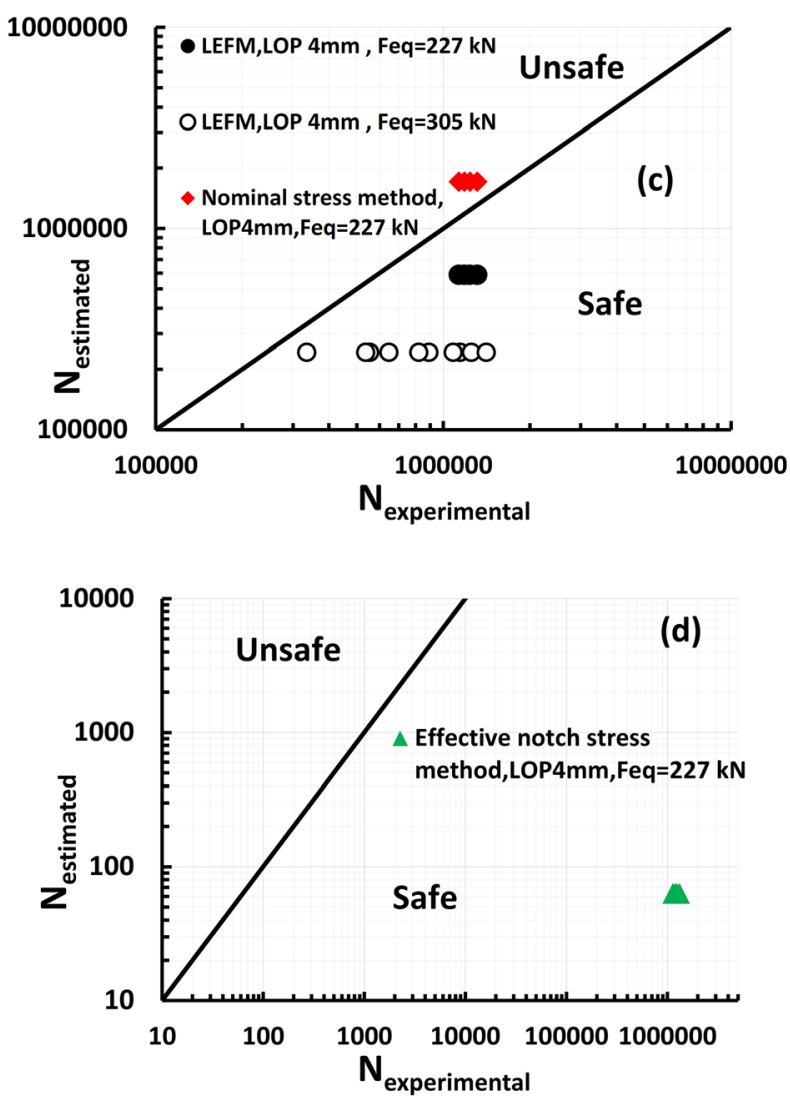

experiment. c Correlation between experiments. Effective notch stress and LEFM. d Correlation between experiments and nominal stress method 
Table 6 Summary of calculated fatigue life for MTA reference structure

\begin{tabular}{|c|c|c|c|c|c|c|c|}
\hline \multirow[t]{2}{*}{ Case } & \multirow[t]{2}{*}{ Crack width $^{\mathrm{a}}$} & \multirow[t]{2}{*}{$\mathrm{LOP}^{\mathrm{a}}$} & \multirow[t]{2}{*}{ Final depth ${ }^{\mathrm{a}}$} & \multicolumn{2}{|c|}{ Total cycles ${ }^{\mathrm{b}}$} & \multicolumn{2}{|c|}{ Averaged total cycles ${ }^{\mathrm{c}}$} \\
\hline & & & & $p_{f}=50 \%$ & $p_{f}=2.3 \%$ & $p_{f}=50 \%$ & $p_{f}=2.3 \%$ \\
\hline $1^{d}$ & 198 & 4 & 15.5 & 102,841 & 29,609 & $1,162,863$ & 334,790 \\
\hline $2^{d}$ & 40 & 4 & 15.4 & 589,198 & 169,635 & 567,785 & 163,487 \\
\hline $3^{d}$ & 198 & 0.5 & 15.5 & 311,108 & 89,571 & $1,922,048$ & 553,351 \\
\hline $4^{\mathrm{d}}$ & 40 & 0.5 & 15.4 & 838,979 & 241,548 & 831,858 & 239,528 \\
\hline $1^{\mathrm{e}}$ & 198 & 4 & 15.5 & 42,398 & 12,206 & 710,124 & 204,435 \\
\hline $2^{\mathrm{e}}$ & 40 & 4 & 15.4 & 242,907 & 69,935 & 234,198 & 67,434 \\
\hline $3^{\mathrm{e}}$ & 198 & 0.5 & 15.5 & 128,259 & 36,927 & $1,246,229$ & 358,797 \\
\hline $4^{e}$ & 40 & 0.5 & 15.4 & 345,882 & 99,582 & 343,105 & 98,781 \\
\hline
\end{tabular}

${ }^{\mathrm{a}}$ Dimensions are in $\mathrm{mm}$

${ }^{\mathrm{b}}$ The life is calculated numerically on the path for $50 \%$ normalized distance

${ }^{\mathrm{c}}$ The average number of cycles per crack step is calculated in FRANC3D using multiple variable degree of freedom approach

${ }^{\mathrm{d}}$ Equivalent load, $F_{\text {eq }}=227 \mathrm{kN}$

${ }^{\mathrm{e}}$ Load, $F=305 \mathrm{kN}$

stress method is very similar to the life estimated by LEFM for the $4 \mathrm{~mm}$ LOP full length crack case (102,841 cycles). The more realistic case is LOP $4 \mathrm{~mm}$ and intermediate crack. For this case only, LEFM can be used which estimates the fatigue strength quite well. The estimations are on the safe side and less conservative in comparison to the fatigue strength estimations with effective notch stress method or full length $4 \mathrm{~mm}$ LOP LEFM.

\section{Parametric study}

In order to find a better design configuration, variation of three parameters and their effect on total fatigue life of the box structure was investigated. These three parameters are thickness of flanges (30, 40, and $60 \mathrm{~mm}$ ), thickness of webs ( 8 and $10 \mathrm{~mm}$ ) and position of hole on flange resulting in centric and eccentric loading mode. Examples of new geometries with their assigned names and corresponding dimensions are summarized in Table 1. The procedure for strength analysis, crack insertion, finding critical side, crack propagation, and fatigue life estimation described in Section 5 is repeated to evaluate the life of the new box structure configurations based on parameters.

\subsection{Influence of flange thickness}

The effect of flange thickness on the fatigue behavior of boxwelded structures, with geometries MTB and MTC, was investigated for all crack types described in Section 5.1 and

Table 7 Results summary of nominal and effective notch stress methods [14]

\begin{tabular}{lllll}
\hline & \multicolumn{2}{l}{ Nominal stress method ${ }^{\mathrm{a}}$} & & \multicolumn{2}{l}{ Effective notch stress method } \\
\cline { 2 - 5 } Penetration & Full & Partial & Full & Partial \\
\hline LOP $^{\mathrm{b}}$ & 0 & 4 & 0 & $\mathrm{C}$ \\
Case & $\mathrm{A}$ & $\mathrm{C}$ & $\mathrm{A}$ & 142.1 \\
Load $^{\mathrm{b}}$ & 196 & 142.1 & 196 & 225 \\
FAT $^{\mathrm{b}}$ & 71 & 36 & 225 & 609.75 \\
Maximum principal stress $^{\mathrm{b}}$ & 46.39 & 32.5 & 475.94 & 24,651 \\
$N_{\text {assessed, } e q}\left(P_{f}=2.3 \%\right)$ & $4,615,541$ & 666,795 & 136,023 & 63,385 \\
$N_{\text {assessed, } e q}\left(P_{f}=50 \%\right)^{\mathrm{b}, \mathrm{c}}$ & $11,868,184$ & $1,714,564$ & 349,763 & \\
\hline
\end{tabular}

${ }^{\mathrm{a}}$ Based on FEA

${ }^{\mathrm{b}}$ Dimensions are in $\mathrm{mm}, \mathrm{kN}, \mathrm{MPa}$, and cycles

${ }^{\mathrm{c}}$ Modified for $50 \%$ failure probability with multiplication by 1.37 correction factor 


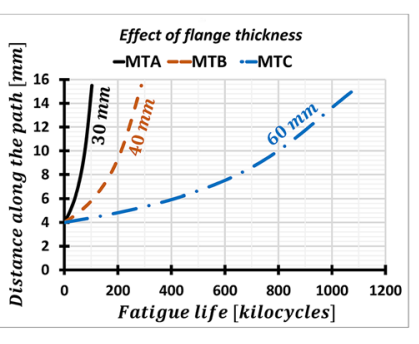

Case 1 (full-length , LOP $4 \mathrm{~mm}$ )

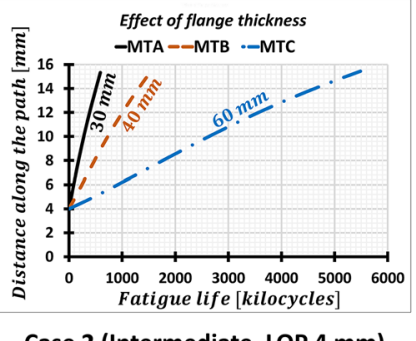

Case 2 (Intermediate, LOP $4 \mathrm{~mm}$ )

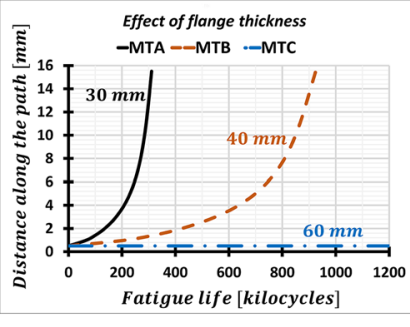

Case 3 (full-length , LOP $0.5 \mathrm{~mm}$ )

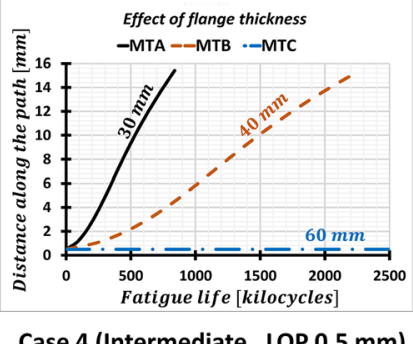

Case 4 (Intermediate, LOP $0.5 \mathrm{~mm}$ )

Fig. 8 Effect of flange thickness on fatigue life $\left(p_{f}=50 \%\right)$ for different initial crack size

compared with the reference box (MTA). Figure 8 pertain to $50 \%$ failure probability, showing the number of cycles when cracks extend to about three fourths of the total thickness. It is observed that the results are qualitatively similar in all four cases and increasing the flange thickness improves the fatigue behavior of box structure. However, it should be noted that in full penetration weld status (Case 3 and 4 ) the flange thickness of $60 \mathrm{~mm}$ leads to infinite fatigue life since the SIFs along the initial crack front are below the threshold value and crack does not propagate through the wall thickness.

Table 8 shows the fatigue life for various cases at final crack length of $15.5 \mathrm{~mm}$. It can be seen that when the flange thickness is increased from $30 \mathrm{~mm}$ (MTA) to $40 \mathrm{~mm}$ (MTB) the fatigue life is increased 2.79 times for case 1, 2.61 times in case 2, 2.97 times in case 3, and 2.70 times in case 4 . When the flange thickness is increased from $30 \mathrm{~mm}$ (MTA) to $60 \mathrm{~mm}$ (MTC) the increase in life in case 3 and 4 is infinite. However; the increase in life in case 1 is 10.73 times and case 2 is 9.31 times. The increase in flange thickness makes the box-welded structure stiff. Deformation at the flange is decreased which also reduces stresses in the weld root and hence increases the fatigue strength.

\subsection{Influence of web thickness}

The effect of web thickness on the fatigue behavior of box structure, with geometry MTD, was investigated for all crack types and compared with the reference box (MTA). Figure 9 shows that the fatigue strength of the welded joint decreases insignificantly with the reduction of $2 \mathrm{~mm}$ in the thickness of web plates. It can be seen that final length of the crack in MTD is $13.74 \mathrm{~mm}$ in comparison to $15.4 \mathrm{~mm}$ in MTA. The reduction in thickness of the web plate leads to increase in the stresses in the box structure. These factors such as higher stresses and lower final crack length cause a reduction in the fatigue strength. The fatigue strength reduces 1.51 times in case $1,1.28$ times in case $2,1.12$ times in case 3 , and 1.26 times in case 4 , see Table 8 .

\subsection{Influence of load position}

Another significant parameter affecting the fatigue strength of box structure is the location of applied load. The influence of load position can be determined by changing the hole place on a flange. Accordingly, the hole was moved $30 \mathrm{~cm}$ toward the critical web plate and LEFM analysis was performed to evaluate the effect of eccentric load on the fatigue life. In Fig. 10, the comparison of MTE and MTF configurations with the reference structure indicates that eccentric loading decreases the fatigue life when the flange thickness remains constant. If the flange thickness is increased and the load is applied eccentrically, it is possible to increase the fatigue life to the fatigue life of reference box structure.

The fatigue life at final crack length is tabulated in Table 8. It can be observed for MTE that the fatigue life reduces 3.08 times in case 1, 3.22 times in case 2, 3.03 times in case 3, and 3.28 times in case 4 in comparison to MTA. The flange thickness in MTF is increased to $40 \mathrm{~mm}$ in comparison to MTE from $30 \mathrm{~mm}$. The fatigue life in all cases is similar to the fatigue life in MTA.

\section{Conclusion}

The conclusions based on the work performed in this study can be summarized into the following:

Table 8 Parametric study, estimated fatigue life MTA, MTB, MTC, MTE, and MTF

\begin{tabular}{|c|c|c|c|c|c|c|}
\hline & MTA & MTB & MTC & MTD & MTE & MTF \\
\hline Estimated fatigue life case 3 (cycles) & 311,108 & 925,034 & Infinite & 275,370 & 102,480 & 304,010 \\
\hline Estimated fatigue life case 1 (cycles) & 102,841 & 287,933 & $1,103,500$ & 67,768 & 33,366 & 96,467 \\
\hline Estimated fatigue life case 4 (cycles) & 838,979 & $2,265,700$ & Infinite & 664,850 & 255,420 & 731,070 \\
\hline Estimated fatigue life case 2 (cycles) & 589,198 & $1,538,700$ & $5,486,300$ & 458,650 & 182,450 & 517,390 \\
\hline
\end{tabular}




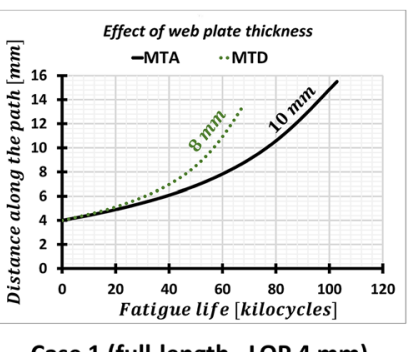

Case 1 (full-length , LOP $4 \mathrm{~mm}$ )

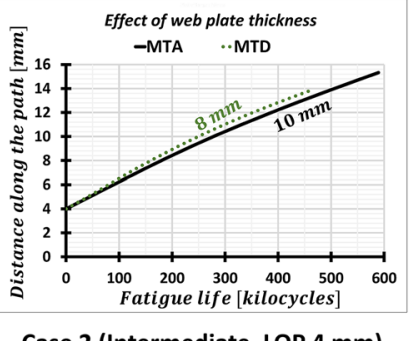

Case 2 (Intermediate, LOP $4 \mathrm{~mm}$ )

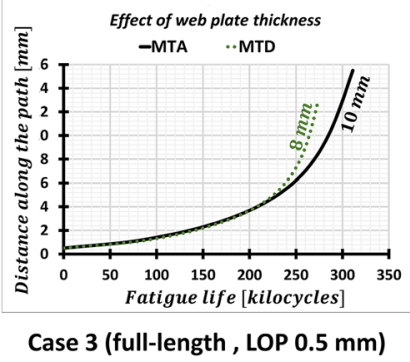

Case 3 (full-length , LOP $0.5 \mathrm{~mm}$ )

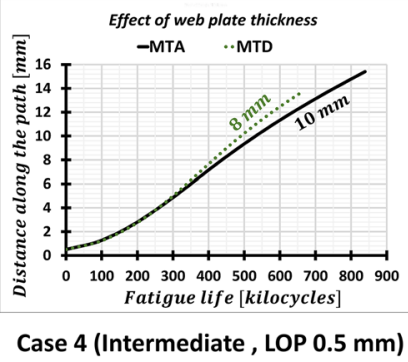

Fig. 9 Effect of web plate thickness on fatigue life $\left(p_{f}=50 \%\right)$ for different initial crack size

- In the box structure, the nearest side to the load application surface is the most critical region for crack initiation and growth.

- Considering the effective stress intensity factor (SIF) $K_{I}$, it is possible to correlate fatigue life with LEFM on the welded box structure with a large initial root defect.

- The influence of initial crack size on the life of root failure is significant. The life decreased considerably by increasing the initial crack size/LOP from 0.5 to $4 \mathrm{~mm}$, specifically for full-length crack LEFM models.

- For the throughout LOP along the web plate (case 1 and 3 ), crack propagates faster in the middle, where the load is concentrated. Due to higher stiffness and constraints, the SIF $K_{I}$ is negligible at the corners. For the intermediate LOP (case 2 and 4), crack propagates faster on the crack front edges compared to the middle. $K_{I}$ tends to increase in the center of the crack after several incremental extensions, but it is arrested at a certain depth.

- Considering the experiment results, the LEFM approach can capture the crack propagation from the weld root reasonably well under the given conditions and estimate the residual fatigue life of box structure conservatively. Compared to the other fatigue assessment methods such as nominal or notch effective stress method, LEFM can determine the residual life more accurately, especially for intermediate LOP. Compared to fatigue life determined experimentally for the box-shaped welded structure, the LEFM fatigue life estimation of an intermediate weld root crack is 4 times more conservative for partial penetration and 1.47 times more conservative for full penetration case.
- The box-shaped structure properties, such as bending stiffness and geometric configurations, have a significant influence on crack behavior. Selection of larger thickness for flange and web plates has a constructive effect while the eccentric load application play an inverse role in fatigue resistance of box structure. When the flange thickness is increased from $30 \mathrm{~mm}$ (MTA) to $40 \mathrm{~mm}$ (MTB), the fatigue life is increased between 2.16 and 2.97 times for all cases. When the web plate thickness is reduced by $2 \mathrm{~mm}$, the fatigue strength reduces 1.12 to 1.51 times for all cases.

- MDVF approach used in Franc3D is not applicable for evaluating the fatigue strength of shallow cracks, e.g., for full-length crack, it is estimated that a life of $1,162,863$ cycles at failure probability is $50 \%$, while when life is calculated with $50 \%$ normalized crack front distance, it is 102,841 cycles.

Acknowledgments Open access funding provided by Royal Institute of Technology. Dr. Bruce J Carter from Fracture Analysis Consultants is also acknowledged for his technical support with the software FRANC3D.

Funding information Sweden's Innovation Agency VINNOVA is gratefully acknowledged for financial support of project VariLight through Grant Number 2016-03363.

Open Access This article is licensed under a Creative Commons Attribution 4.0 International License, which permits use, sharing, adaptation, distribution and reproduction in any medium or format, as long as you give appropriate credit to the original author(s) and the source, provide a link to the Creative Commons licence, and indicate if changes were made. The images or other third party material in this article are included in the article's Creative Commons licence, unless indicated otherwise in a

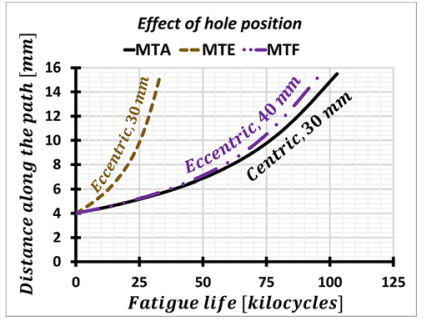

Case 1 (full-length, LOP $4 \mathrm{~mm}$ )

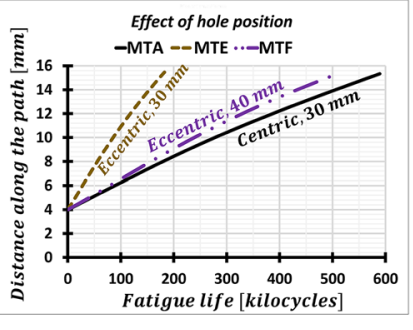

Case 2 (Intermediate, LOP $4 \mathrm{~mm}$ )

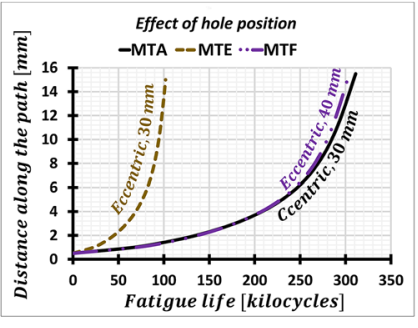

Case 3 (full-length , LOP $0.5 \mathrm{~mm}$ )

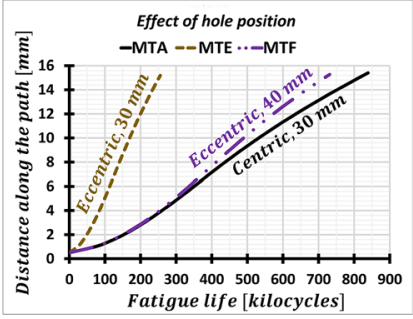

Case 4 (Intermediate, LOP $0.5 \mathrm{~mm}$ )

Fig. 10 Effect of hole position on fatigue life $\left(p_{f}=50 \%\right)$ for different initial crack size 
credit line to the material. If material is not included in the article's Creative Commons licence and your intended use is not permitted by statutory regulation or exceeds the permitted use, you will need to obtain permission directly from the copyright holder. To view a copy of this licence, visit http://creativecommons.org/licenses/by/4.0/.

\section{References}

1. Hobbacher AF (2016) Recommendations for fatigue design of welded joints and components. 2nd edn. Springer International Publishing. doi:https://doi.org/10.1007/978-3-319-23757-2

2. Peeker E (1997) Extended numerical modeling of fatigue behavior. Lausanne, EPFL

3. Paris P, Gomez M, Anderson W (1961) A rational analytic theory of fatigue. The Trend, Eng

4. Franc3d (2018) Reference manual version 7.3. Fracture Analysis Consultants Inc.,

5. Fricke W (2013) IIW guideline for the assessment of weld root fatigue. Weld World 57(6):753-791. https://doi.org/10.1007/ s40194-013-0066-y

6. Radaj D, Sonsino CM, Fricke W Fatigue assessment of welded joints by local aproaches, 2nd edn. CRC press ISBN-13:978-0 8493-8451-6, Boca Raton

7. Frank KH, Fisher JW (1979) Fatigue strength of fillet welded cruciform joints. J Struct Div 105(9):1727-1740

8. Guha B (1995) A new fracture mechanics method to predict the fatigue life of welded cruciform joints. Eng Fract Mech 52(2):215229. https://doi.org/10.1016/0013-7944(95)00004-f

9. Petinov SV, Kim WS, Paik YM (2006) Assessment of fatigue strength of weld root in ship structure: an approximate procedure. Ships Offshore Struct 1(1):55-60. https://doi.org/10.1533/saos. 2005.0002

10. Barsoum Z, Barsoum I (2009) Residual stress effects on fatigue life of welded structures using LEFM. Eng Fail Anal 16(1):449-467. https://doi.org/10.1016/j.engfailanal.2008.06.017

11. Mori T (2008) Evaluation formula for fatigue strength of cruciform welded joints failing from weld roots under bi-axial loading. Steel Struct 8:143-153

12. Aygül M, Al-Emrani M, Barsoum Z, Leander J (2014) Investigation of distortion-induced fatigue cracked welded details using 3D crack propagation analysis. Int J Fatigue 64:54-66

13. Triamlumlerd W, Lenwari A (2017) Analysis of fatigue crack propagation in steel I-beams with welded transverse stiffeners subjected to in-plane loadings. Eng J 21(4):307-324

14. Haglund P, Khurshid M, Barsoum Z (2019) Mapping of scatter in fatigue life assessment of welded structures - a Round Robin study. IIW document XIII-2827-19

15. Zerbst U, Madia M, Beier HTH (2017) Fatigue strength and life determination of weldments based on fracture mechanics. Procedia Struct Integr 7:407-414. https://doi.org/10.1016/j.prostr.2017.11. 106

16. Sonsino CM. Evaluation of residual stresses on welded joints with regard to loading mode, local geometry and post weld treatments.IIW-Doc. No. X-1638-08 / XIII-2215-08 / XV-1284-08
17. Zhu J, Khurshid M, Barsoum Z (2019) Assessment of computational weld mechanics concepts for estimation of residual stresses in welded box structures. Procedia Struct Integr 17:704-711. https:// doi.org/10.1016/j.prostr.2019.08.094

18. International A (2015) ASTM E647-15e1, Standard test method for measurement of fatigue crack growth rates. West Conshohocken, PA

19. Irwin GR (1957) Relation of stresses near a crack to the crack extension force. 9th Cong app Mech, Brussels

20. Irwin GR (1957) Analysis of stresses and strains near the end of a crack traversing a plate. J Appl Mech Trans ASME 24:361-364

21. Yau JF, Wang SS, Corten HT (1980) A mixed-mode crack analysis of isotropic solids using conservation Laws of elasticity. 47 (2):335. https://doi.org/10.1115/1.3153665

22. Singh R, Carter BJ, Wawrzynek PA, Ingraffea AR (1998) Universal crack closure integral for SIF estimation. Eng Fract Mech 60(2):133-146

23. Moore P, Booth G (2015) 12 - Weld fatigue assessment. In: Moore $P$, Booth $G$ (eds) The welding engineer's guide to fracture and fatigue. Woodhead Publishing, Oxford, pp 175-184. doi: https:// doi.org/10.1533/9781782423911.2.175

24. Stephens RI, Fatemi A, Stephens RR, Fuchs HO Metal fatigue in engineering, 2nd edn. John Wiley \& Sons ISBN 978-0-47151059-8

25. Tanaka Y, Soya I (1990) Fatigue crack propagation behaviour of various types of steels for welded structures. Weld Int 4 (7):528 534

26. Elber W (1971) The significance of fatigue crack closure: damage tolerance in aircraft structures. ASTM International, West Conshohocken. https://doi.org/10.1520/STP26680S

27. Zerbst U (2020) Application of fracture mechanics to welds with crack origin at the weld toe - a review. Part 2: welding residual stresses. Residual and total life assessment. Weld World 64:151169

28. Chapetti MD, Jaureguizahar LF (2011) Estimating the fatigue behaviour of welded joints. Procedia Eng 10:959-964. https://doi.org/ 10.1016/j.proeng.2011.04.158

29. Radaj D, Sonsino CM, Fricke W, Institute of Materials M, Mining (2006) Fatigue assessment of welded joints by local approaches, 2nd edn. Woodhead Publishing Ltd., United Kingdom. https://doi. org/10.1533/9781845691882

30. Wawrzynek P, Carter B, Hwang C-Y, Ingraffea A (2010) Advances in simulation of arbitrary 3D crack growth using FRANC3Dv5. J Comput Struct Eng Inst Korea 23(6):607-613

31. Erdogan F, Sih GC (1963) On the crack extension in plates under plane loading and transverse shear. J Basic Eng 85(4):519-525. https://doi.org/10.1115/1.3656897

32. Standard B (2015) BS 7910: 2013+ A1: 2015 Guide to methods for assessing the acceptability of flaws in metallic structures. BSI Stand Publ, London, UK

33. Pettersson G, Barsoum Z (2012) Finite element analysis and fatigue design of a welded construction machinery component using different concepts. Eng Fail Anal 26:274-284

Publisher's note Springer Nature remains neutral with regard to jurisdictional claims in published maps and institutional affiliations. 